\title{
Vascular response profiles following a nano polymer-free sirolimus-eluting stent implantation assessed by optical coherence tomography in a porcine model
}

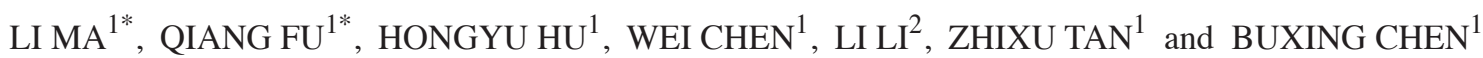 \\ ${ }^{1}$ Department of Cardiology, Beijing Tiantan Hospital, Capital Medical University, Beijing 100050; \\ ${ }^{2}$ Department of Pathology, National Center for Cardiovascular Disease, Fuwai Cardiovascular Hospital, \\ Chinese Academy of Medical Sciences and Peking Union Medical College, Beijing 100037, P.R. China
}

Received July 5, 2015; Accepted September 1, 2016

DOI: $10.3892 /$ etm.2017.4061

\begin{abstract}
Optical coherence tomography (OCT) is a high resolution imaging modality and has been considered as the ideal tool for the evaluation of neointimal tissue and vascular responses following stent implantation. However, vascular response profiles following the implantation of a novel nano polymer-free sirolimus-eluting stent (SES) assessed by OCT has not been fully investigated. Therefore, the aim of the present study was to determine the effects of a nano polymer-free SES on neointimal formation using OCT. A total of 16 nano polymer-free SESs were implanted in the coronary arteries of 8 pigs. At $3(n=4)$ or 6 months $(n=4)$, the animals were euthanized following OCT evaluation and the stented arterial segments were analyzed by histological analysis. Neointimal area, thickness and burden were evaluated by OCT. In addition, strut-associated inflammation, stent endothelialization and arterial injury were investigated by histomorphological analysis. OCT examination showed that at 6 months, neointimal thickness $(193.3 \pm 109.5$ vs. $167.2 \pm 119.7 \mu \mathrm{m}, \mathrm{P}=0.023)$ and neointimal burden $(29.3 \pm 14.3$ vs. $24.8 \pm 17.4 \%, \mathrm{P}=0.006)$ significantly increased compared with at 3 months. Histomorphological analysis indicated that the endothelialization score was significantly greater at 6 months compared with at 3 months ( $2.85 \pm 0.36$ vs. $2.52 \pm 0.60, \mathrm{P}<0.001)$. However, at 3 months, nano polymer-free SES showed a significantly higher inflammatory score $[0(0,1)$ vs. $0(0,0), \mathrm{P}<0.001]$ compared with at 6 months. In conclusion, nano polymer-free SES achieves endothelialization at 3 months; however, neointimal proliferation is more
\end{abstract}

Correspondence to: Dr Buxing Chen, Department of Cardiology, Beijing Tiantan Hospital, Capital Medical University, 6 Tiantanxili, Beijing 100050, P.R. China

E-mail: chbux@126.com

${ }^{*}$ Contributed equally

Key words: nano, polymer-free, drug-eluting stent, optical coherence tomography, histomorphology significant at 6 months and may be attributed to strut-associated inflammation.

\section{Introduction}

Drug-eluting stents (DESs) have been widely used for interventional therapy in patients with coronary artery disease, since they remarkably reduce in-stent restenosis compared with bare metal stents $(1,2)$. However, the risk of late and very late stent thrombosis remains and is associated with delayed vascular healing and impaired endothelialization due to the lack of biodegradation of the polymer coatings and potentially polymer-related inflammation and hypersensitivity following stent implantation (3-5). To improve the biosafety, several biocompatible or biodegradable polymers within novel DESs have been developed. The polymer-free DES has since been proven to be an appropriate method to suppress neointimal proliferation and minimize polymer-associated adverse effects. Furthermore, excellent mechanical flexibility and biocompatibility, in addition to stable drug release performance, have been demonstrated in DESs with a nanostructured coating in vitro (6-8). The nano polymer-free sirolimus-eluting stent (SES) is a novel polymer-free DES with a nanoporous surface that can act as an adjuvant for drugs and provide better re-endothelialization and inhibition of neointimal proliferation (9). Optical coherence tomography (OCT) is a high resolution imaging modality and has been considered as the ideal tool for the evaluation of neointimal tissue and vascular responses following stent implantation in vivo (10-13). However, it is unclear whether a lack of polymer induces a different vascular response in drug-eluting stents and vascular response profiles following nano polymer-free SES implantation assessed by OCT have not been investigated.

Therefore, the aim of our study was to determine the effects of nano polymer-free SES on neointimal formation using by OCT.

\section{Materials and methods}

Study design. A total of 8 male juvenile Chinese pigs with a body weight between 20 and $30 \mathrm{~kg}$ were used in the present 
study. These were were obtained from the Experimental Pig Production Institute (Fangshan District, Beijing, China) and were maintained at $18-25^{\circ} \mathrm{C}, 40-60 \%$ humidity, with $>10 \mathrm{~h}$ of light every day; food was provided twice a day at 2-3\% of the pigs' total weight, and free access to water was provided. Nano polymer-free SES (Lepu Medical Technology Co., Ltd., Beijing, China) were randomly implanted in the right coronary artery, left anterior descending or left circumflex coronary artery with two stents in each porcine model (one stent per vessel). In order to assess different stages of neointimal formation, all animals were divided into two groups: Follow-up after stent implantation of $3(n=4)$ or 6 months $(n=4)$. At the follow-up time point, the animals were sacrificed following completion of coronary angiography and OCT evaluation to obtain specimens for histological analysis of stented arterial segments. The study protocol was approved by the Institutional Animal Care and Use Committee at Beijing Tiantan Hospital (Beijing, China).

Coronary interventional procedure. Three days prior to the coronary procedure, animals were administered $300 \mathrm{mg}$ aspirin (Bayer, Newbury, UK) and $75 \mathrm{mg}$ clopidogrel (Sanofi S.A., Paris, France). Thereafter, antiplatelet therapy of $75 \mathrm{mg}$ clopidogrel and $100 \mathrm{mg}$ aspirin was administered daily throughout the study in all animals.

Animals were anesthetized with $0.1-0.2 \mathrm{mg} / \mathrm{kg}$ midazolam (Nhwa Pharmaceutical Co., Ltd., Jiangsu, China) and 0.25-0.3 ml/kg xylazine (Sangon Biological Engineering Co. Ltd., Shanghai, China) and an arterial sheath (6 French; Cordis Corporation, Hialeah, FL, USA) was placed in the right femoral artery by cut-down with a sterile technique. Coronary catheterization was performed following administration of intravenous heparin (5,000 units). Baseline angiography was acquired and all stents were placed at a targeted 1.1:1 to 1.2:1 stent-to-vessel ratio compared with the reference vessel diameter to induce a moderate vessel injury and promote neointimal formation. Stents of 14,15 or $18 \mathrm{~mm}$ length and diameters of 2.5, 2.75 and $3.0 \mathrm{~mm}$ were implanted according to the coronary artery size.

OCT acquisition and analysis. Frequency domain (FD)-OCT imaging was performed using the C7-XR OCT intravascular imaging system (LightLab Imaging, Inc., Westford, MA, USA). During FD-OCT image acquisition, a continuous non-occlusive contrast as a flush was administrated to replace coronary blood flow and automatic pullbacks were performed at a rate of $20 \mathrm{~mm} / \mathrm{sec}$ and 100 frames/sec. Off-line OCT analysis was performed with LightLab Imaging software (LightLab Imaging, Inc.).

For quantitative analysis, cross-sectional OCT images were analyzed at 1-mm longitudinal steps throughout the pullback from distal stent edge to proximal stent edge. OCT images were excluded from the analysis if stent struts were not visible on the screen, bifurcation cross-sections had side branches or if residual blood was mistaken for neointimal tissue. The lumen and stent were manually traced and stent struts were positioned manually in the center of the stent strut which showed a bright 'blooming' appearance (14). The following parameters were measured: Minimal luminal diameter, luminal area, stent area, neointimal area (stent area - lumen area) and neointimal burden (mean neointimal area / mean stent area x 100\%). To analyze neointimal thickness, the distance between the center of each stent strut and the luminal border was measured in the direction of the center of gravity.

Quantitative analyses of all OCT images were performed by two independent investigators who were blinded to the angiographic data and clinical presentations.

Interobserver variability. Two independent investigators analyzed 50 cross-sectional images without artifacts. Inter-observer agreement was determined by calculating values for differences in measurements of neointimal area and neointimal thickness.

Histological analysis. All animals were sacrificed following follow-up coronary angiography and OCT imaging; this was performed using intravenously administered $30 \mathrm{ml} \mathrm{10 \%}$ potassium chloride. Immediately following sacrifice, the hearts were excised and the stented coronary artery segments were harvested from the heart by careful dissection, fixed by immersion in $10 \%$ formalin, dehydrated in a graded series of ethanol and embedded in methyl methacrylate resin (Huayi Acrylic Acid Co., Ltd., Shanghai, China). Following polymerization, sections measuring $\sim 1.3 \mathrm{~mm}$ were sawed from each stent, beginning at the distal stent edge. The artery-stent specimens were cut on a rotary microtome at $100 \mu \mathrm{m}$ from the proximal through the distal margin of the stent and stained with hematoxylin and eosin, and elastic Van Gieson stains. There were no histological sections lost due to processing, and all sections were of excellent quality. Morphometric analysis was performed by Image-Pro Plus version 6.0 software (Media Cybernetics, Inc., Rockville, MD, USA). Morphologic analysis of strut-associated inflammation, stent endothelialization and arterial injury were completed using previously described methods $(3,15,16)$. Briefly, the inflammatory score for each individual strut was graded as follows: 0 , No inflammatory cells surrounding the strut; 1 , light, non-circumferential lymphohistiocytic infiltrate surrounding the strut; 2, localized, moderate-to-dense cellular aggregate surrounding the strut noncircumferentially; and 3, circumferential dense lymphohistiocytic cell infiltration of the strut. The stent endothelialization score was defined as the extent of the circumference of the arterial lumen covered by endothelial cells and was scored between 1 and 3 (1, 25\%;2, 25 to $75 \% ; 3,>75 \%)$. The intimal fibrin content was graded as follows: 1 , Focal residual fibrin involving any portion of the artery and for moderate fibrin deposition adjacent to the strut involving $25 \%$ of the circumference of the artery; 2, moderate fibrin deposition involving $25 \%$ of the circumference of the artery or heavy deposition of fibrin adjacent to and between stent struts involving $25 \%$ of the circumference of the artery; or 3 , heavy deposition of fibrin involving $25 \%$ of the circumference of the artery. The intimal smooth muscle cell (SMC) content was scored as follows: 1, Sparse SMC density involving any portion of the artery and for moderate SMC infiltration less than the full thickness of the neointima involving $<25 \%$ of the circumference of the artery; 2, moderate SMC infiltration less than the full thickness of the neointima involving $>25 \%$ of the circumference of the artery, or dense SMC content the full thickness of the neointima involving $<25 \%$ of the circumference of the artery; 
Table I. Pig survival time and stent characteristics.

\begin{tabular}{|c|c|c|c|c|c|}
\hline Pig no. & Survival time & Stent-1 location & Stent-1 size & Stent-2 location & Stent-2 size \\
\hline 1 & 6 months & $\mathrm{LCX}$ & $2.75 \times 18 \mathrm{~mm}$ & RCA & $2.75 \times 18 \mathrm{~mm}$ \\
\hline 2 & 6 months & $\mathrm{LCX}$ & $2.75 \times 14 \mathrm{~mm}$ & $\mathrm{RCA}$ & $2.5 \times 14 \mathrm{~mm}$ \\
\hline 3 & 6 months & LAD & $2.5 \times 18 \mathrm{~mm}$ & RCA & $2.5 \times 15 \mathrm{~mm}$ \\
\hline 4 & 6 months & LCX & $2.5 \times 15 \mathrm{~mm}$ & RCA & $2.5 \times 18 \mathrm{~mm}$ \\
\hline 5 & 3 months & LCX & $2.75 \times 15 \mathrm{~mm}$ & $\mathrm{RCA}$ & $2.75 \times 15 \mathrm{~mm}$ \\
\hline 6 & 3 months & LCX & $2.5 \times 15 \mathrm{~mm}$ & RCA & $3.0 \times 18 \mathrm{~mm}$ \\
\hline 7 & 3 months & LCX & $2.75 \times 18 \mathrm{~mm}$ & $\mathrm{RCA}$ & $2.75 \times 18 \mathrm{~mm}$ \\
\hline 8 & 3 months & LAD & $2.5 \times 18 \mathrm{~mm}$ & $\mathrm{RCA}$ & $2.5 \times 18 \mathrm{~mm}$ \\
\hline
\end{tabular}

LCX, left circumflex coronary artery; LAD, left anterior descending coronary artery; RCA, right coronary artery.

or 3, dense SMC content the full thickness of the neointima involving $>25 \%$ of the circumference of the artery.

All histomorphological analyses were performed by a single independent investigator blinded to the study.

Statistical analysis. Variables were analyzed for normal distribution using the Kolmogorov-Smirnov test. Continuous values following a normal distribution were expressed as the mean \pm standard deviation, and those not normally distributed were indicated as the median with interquartile range. Categorical variables were expressed as frequencies and percentages. Differences between the two groups were determined using Student's t-test or Mann-Whitney U test, as appropriate for continuous variables. The $\chi^{2}$ test or Fisher exact test was used as appropriate to compare categorical variables. Agreement between the two observers (interobserver variability) was investigated using kappa analysis. $\mathrm{P}<0.05$ was considered to indicate a statistically significant difference. Statistical analyses were performed using SPSS version 20.0 software (IBM SPSS, Armonk, NY, USA).

\section{Results}

General findings. A total of 16 nano polymer-free SES were successfully implanted in the coronary arteries of 8 pigs. All pigs survived without problems until sacrifice. The survival time of pigs and stent characteristics are presented in Table I.

OCT quantitative analysis. The results of OCT quantitative analysis of the stents are presented in Table II. Lumen area $\left(2.73 \pm 0.66\right.$ vs. $\left.3.00 \pm 0.65 \mathrm{~mm}^{2}, \mathrm{P}<0.001\right)$ and stent area $\left(3.86 \pm 0.39\right.$ vs. $\left.4.05 \pm 0.59 \mathrm{~mm}^{2}, \mathrm{P}<0.001\right)$ at 6 months were significantly smaller compared with those at 3 months. In addition, at 6 months, neointimal thickness $(193.3 \pm 109.5$ vs. $167.2 \pm 119.7 \mu \mathrm{m}, \mathrm{P}=0.023)$ and neointimal burden $(29.3 \pm 14.3$ vs. $24.8 \pm 17.4 \%, \mathrm{P}=0.006)$ significantly increased compared with at 3 months; neointimal area increased from between 3 and 6 months, but this difference was not significant.

Reproducibility of qualitative OCT analysis. Interobserver variability for the quantitative OCT assessment showed good concordance: $\mathrm{k}=0.91$ for neointimal area and $\mathrm{k}=0.81$ for neointimal thickness.
Histological analysis. The histomorphometry and semi-quantitative scoring for arterial injury, inflammation and stent endothelialization at 3 and 6 months after nano polymer-free SES implantation are summarized in Table III. Marked stent endothelialization was achieved at 3 and 6 months. However, the endothelialization score was greater at 6 months compared with at 3 months $(2.85 \pm 0.36$ vs. $2.52 \pm 0.60, \mathrm{P}<0.001)$. In addition, at 3 months, nano polymer-free SES showed a significantly higher inflammatory score $[0(0,1)$ vs. $0(0,0), \mathrm{P}<0.001]$ and fibrin score $[0(0,1)$ vs. $0(0,0), \mathrm{P}<0.001]$ compared with at 6 months. There were no significant differences in injury score and intimal smooth muscle cell content between 3 and 6 months. Representative images of OCT and histomorphologic sections at 3 months after nano polymer-free SES implantation are presented in Fig. 1.

\section{Discussion}

The present study reports the vascular response to nano polymer-free SES in a pig coronary model. The primary findings of the present study were that following nano polymer-free SES implantation (1), endothelialization was achieved at 3 months but neointimal proliferation was more significant at 6 months; (2) In addition, strut-associated inflammation was more frequently observed at 3 months compared with at 6 months.

DESs have markedly reduced restenosis compared with bare metal stents, owing to the controlled release of anti-proliferative drugs from polymers (17). However, there is evidence that the durable polymers may lead to delayed vascular healing and reendothelialization, and localized hypersensitivity reactions and inflammation, resulting in a high frequency of in-stent restenosis and/or late stent thrombosis $(4,18-20)$. The most effective solution appears to be the application of drugs to the stent surface without polymers to eliminate the adverse effects associated with the polymer (21). Previously, the polymer-free DES as an emerging technology has been proved to be a feasible and valuable method to inhibit neointimal proliferation without the potential of late polymer-related adverse effects $(7,8)$. The nano polymer-free SES is a polymer-free DES utilizing nanometer-size pore technology, with nanoporous cavities that can be used as drug carriers to store and control the release of anti-proliferative 
Table II. Quantitative optical coherence tomography analysis.

\begin{tabular}{lccr}
\hline Parameter & 3 months (274 sections) & 6 months (305 sections) & P-value \\
\hline Lumen area, $\mathrm{mm}^{2}$ & $3.00 \pm 0.65$ & $2.73 \pm 0.66$ & $<0.001$ \\
Stent area, mm & $4.05 \pm 0.59$ & $3.86 \pm 0.39$ & $<0.001$ \\
Neointimal area, $\mathrm{mm}^{2}$ & $1.06 \pm 0.80$ & $1.12 \pm 0.55$ & 0.35 \\
Neointimal burden, \% & $24.8 \pm 17.4$ & $29.3 \pm 14.3$ & 0.006 \\
Neointimal thickness, $\mu \mathrm{m}$ & $167.2 \pm 119.7$ & $193.3 \pm 109.5$ & 0.023
\end{tabular}

Values are presented as $\mathrm{n}(\%)$ or mean \pm standard deviation.

Table III. Histological analysis.

\begin{tabular}{lccc}
\hline Parameter & 3 months $(189$ sections $)$ & 6 months $(151$ sections $)$ & P-value \\
\hline Inflammation score $^{\mathrm{a}}$ & $0(0,1)$ & $0(0,0)$ & $<0.001$ \\
Injury score & $1.26 \pm 1.07$ & $1.25 \pm 1.01$ & 0.91 \\
Endotheliazation score & $2.52 \pm 0.60$ & $2.85 \pm 0.36$ & $<0.001$ \\
Intimal SMC content $^{\text {Fibrin score }}$ & $2.84 \pm 0.37$ & $2.76 \pm 0.58$ & 0.14 \\
& $0(0,1)$ & $0(0,0)$ & $<0.001$ \\
\hline
\end{tabular}

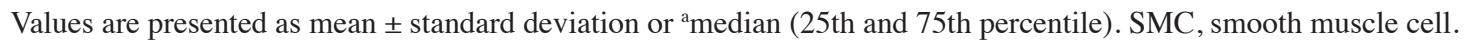

A

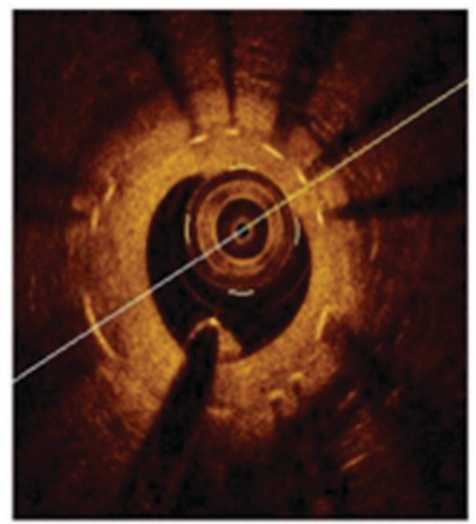

B

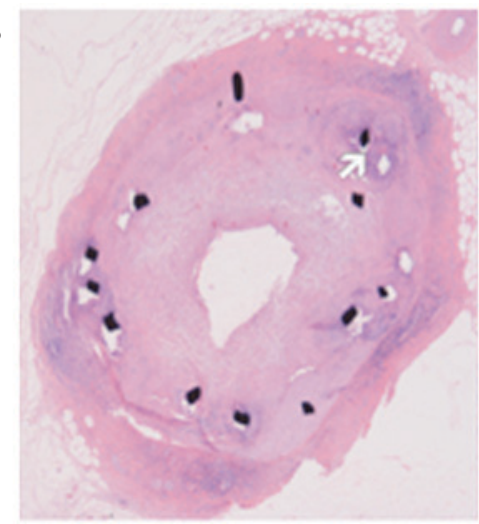

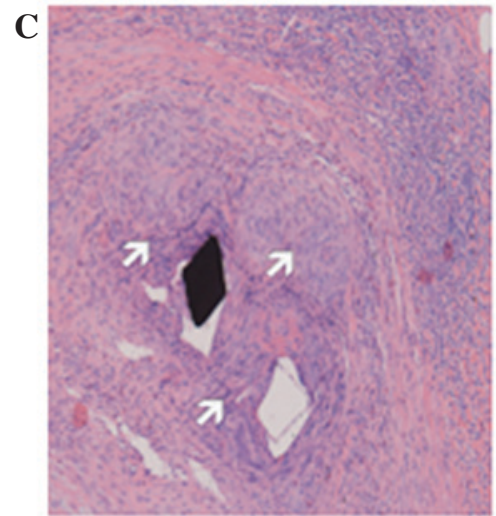

Figure 1. Representative images of (A) optical coherence tomography and histomorphologic sections at (B) $\mathrm{x} 4$ and (C) $\mathrm{x} 20$ magnification with hematoxylin and eosin stain at 3 months after Nano polymer-free sirolimus-eluting stent implantation. Histology shows that a large quantity of lymphocytes were infiltrated around the stent strut. The white arrowheads in (B) and (C) indicate representative strut-associated inflammation.

drugs; kinetic release data indicate that $\sim 85 \%$ of the drug is released within 1 month after nano polymer-free SES implantation (22). Several intravascular ultrasound and histological observations have demonstrated that polymer free SES shows a sustained neointimal suppression and reduced inflammation compared with polymer coated SES $(9,23)$. However, a higher quality of intravascular imaging is required to fully evaluate vascular response following the implantation of nano polymer-free SES.

A previous study performed by the authors of the present study revealed that, as a novel intravascular imaging modality, OCT can provide insights into the characteristics of atherosclerotic plaques and neointimal coverage (24). In addition, the recently developed FD interferometry analysis OCT system allows for faster image acquisition
( $\leq 20 \mathrm{~mm} / \mathrm{sec})$ and greater scan depths that enable its application in large caliber vessels (25). As a result, FD-OCT is the preferred intravascular imaging modality for the in vivo atheromatous plaque characterization, and post-stenting assessment in patients with coronary disease (26). Therefore, the present study evaluated nano polymer-free SES for vascular response, endothelialization and inhibition of neointimal hyperplasia by FD-OCT and pathology in an animal model. The results of the current study demonstrated that nano polymer-free SES effectively inhibits neointimal formation for the first 3 months and that late neointimal formation occurs at 6 months, in part owing to inflammation and cellular proliferation. Previous pharmacokinetic studies have revealed that nano polymer-free SES can effectively deliver drugs to the local coronary artery and release the 
drug rapidly; such a release profile was favorable for rapid endothelialization of nano polymer-free SES (27). Although a previous study demonstrated that polymer free SES showed less inflammation and improved arterial healing in rabbits (22), histology analysis at 3 months in the present study demonstrated a markedly higher level of inflammation. Notably, the fibrin score in the current study increased progressively in 3 months after implantation of nano polymer-free SES. Therefore, the present study demonstrates that chronic inflammation is associated with neointimal formation and may result in further neointimal proliferation over time following nano polymer-free SES placement.

There are a number of limitations of the present study. Firstly, the experimental animal did not develop atherosclerosis and nano polymer-free SESs were implanted in normal coronary arteries. Thus, the results may not interpret arterial response in real-world coronary artery lesions. Secondly, vascular responses of nano polymer-free SES were investigated but were not compared with common polymer-coated SES. Thirdly, the sample size was small and bias existed; therefore, the results can not be simply transferred to clinical practice. Finally, the follow-up duration was short and longer follow-up is required.

In conclusion, nano polymer-free SES achieves endothelialization at 3 months but neointimal proliferation is more significant at 6 months and may be attributed to strut-associated inflammation.

\section{Acknowledgements}

The authors wish to acknowledge the expert technical assistance of the staff at Beijing Pinggu Hospital (Beijing, China) with the animal experimental phases of this study. The present study was funded by Beijing Municipal Commission of Health and Family Planning (grant no. 2011-3-026).

\section{References}

1. Moses JW, Leon MB, Popma JJ, Fitzgerald PJ, Holmes DR, O'Shaughnessy C, Caputo RP, Kereiakes DJ, Williams DO, Teirstein PS, et al; SIRIUS Investigators: Sirolimus-eluting stents versus standard stents in patients with stenosis in a native coronary artery. N Engl J Med 349: 1315-1323, 2003.

2. Stone GW, Ellis SG, Cox DA, Hermiller J, O'Shaughnessy C, Mann JT, Turco M, Caputo R, Bergin P, Greenberg J, et al; TAXUS-IV Investigators: A polymer-based, paclitaxel-eluting stent in patients with coronary artery disease. N Engl J Med 350 221-231, 2004.

3. Joner M, Finn AV, Farb A, Mont EK, Kolodgie FD, Ladich E, Kutys R, Skorija K, Gold HK and Virmani R: Pathology of drug-eluting stents in humans: Delayed healing and late thrombotic risk. J Am Coll Cardiol 48: 193-202, 2006.

4. Camenzind E, Steg PG and Wijns W: Stent thrombosis late after implantation of first-generation drug-eluting stents: A cause for concern. Circulation 115: 1440-1455; discussion 1455, 2007.

5. Nakazawa G, Finn AV, Vorpahl M, Ladich ER, Kolodgie FD and Virmani R: Coronary responses and differential mechanisms of late stent thrombosis attributed to first-generation sirolimus- and paclitaxel-eluting stents. J Am Coll Cardiol 57: 390-398, 2011.

6. Hausleiter J, Kastrati A, Wessely R, Dibra A, Mehilli J, Schratzenstaller T, Graf I, Renke-Gluszko M, Behnisch B, Dirschinger $\mathrm{J}$, et al; Investigators of the Individualizable Durg-Eluting Stent System to Abrogate Restenosis Project: Prevention of restenosis by a novel drug-eluting stent system with a dose-adjustable, polymer-free, on-site stent coating. Eur Heart J 26: 1475-1481, 2005
7. Mehilli J, Kastrati A, Wessely R, Dibra A, Hausleiter J, Jaschke B, Dirschinger J and Schömig A; Intracoronary Stenting and Angiographic Restenosis--Test Equivalence Between 2 Drug-Eluting Stents (ISAR-TEST) Trial Investigators: Randomized trial of a nonpolymer-based rapamycin-eluting stent versus a polymer-based paclitaxel-eluting stent for the reduction of late lumen loss. Circulation 113: 273-279, 2006.

8. Ruef J, Störger H, Schwarz F and Haase J: Comparison of a polymer-free rapamycin-eluting stent (YUKON) with a polymer-based paclitaxel-eluting stent (TAXUS) in real-world coronary artery lesions. Catheter Cardiovasc Interv 71: 333-339, 2008.

9. Chen M, Zheng B, Wu Z, Peng HY, Wang XG, Zhang B and Huo Y: Efficacy and safety of a novel nano-porous polymer-free sirolimus-eluting stent in pigs. Chin Med J (Engl) 126: 4731-4735, 2013.

10. Gonzalo N, Serruys PW, Okamura T, van Beusekom HM, Garcia-Garcia HM, van Soest G, van der Giessen W and Regar E: Optical coherence tomography patterns of stent restenosis. Am Heart J 158: 284-293, 2009.

11. Prati F, Regar E, Mintz GS, Arbustini E, Di Mario C, Jang IK, Akasaka T, Costa M, Guagliumi G, Grube E, et al; Expert's OCT Review Document: Expert review document on methodology, terminology and clinical applications of optical coherence tomography: Physical principles, methodology of image acquisition and clinical application for assessment of coronary arteries and atherosclerosis. Eur Heart J 31: 401-415, 2010.

12. Murata A, Wallace-Bradley D, Tellez A, Alviar C, Aboodi M, Sheehy A, Coleman L, Perkins L, Nakazawa G, Mintz G, et al: Accuracy of optical coherence tomography in the evaluation of neointimal coverage after stent implantation. JACC Cardiovasc Imaging 3: 76-84, 2010.

13. Fu Q, Suzuki N, Kozuma K, Miyagawa M, Nomura T, Kawashima H, Shiratori Y, Ishikawa S, Kyono H and Isshiki T: Quantitative optical coherence tomography analysis for late in-stent restenotic lesions. Int Heart J 56: 13-17, 2015.

14. Guagliumi G, Musumeci G, Sirbu V, Bezerra HG, Suzuki N, Fiocca L, Matiashvili A, Lortkipanidze N, Trivisonno A, Valsecchi O, et al; ODESSA Trial Investigators: Optical coherence tomography assessment of in vivo vascular response after implantation of overlapping bare-metal and drug-eluting stents. JACC Cardiovasc Interv 3: 531-539, 2010.

15. Carter AJ, Aggarwal M, Kopia GA, Tio F, Tsao PS, Kolata R, Yeung AC, Llanos G, Dooley J and Falotico R: Long-term effects of polymer-based, slow-release, sirolimus-eluting stents in a porcine coronary model. Cardiovasc Res 63: 617-624, 2004.

16. Virmani R, Kolodgie FD and Farb A: Drug-eluting stents: Are they really safe? Am Heart Hosp J 2: 85-88, 2004.

17. Stone GW, Moses JW, Ellis SG, Schofer J, Dawkins KD, Morice MC, Colombo A, Schampaert E, Grube E, Kirtane AJ, et al: Safety and efficacy of sirolimus- and paclitaxel-eluting coronary stents. N Engl J Med 356: 998-1008, 2007.

18. Pfisterer M, Brunner-La Rocca HP, Buser PT, Rickenbacher P, Hunziker P, Mueller C, Jeger R, Bader F, Osswald S and Kaiser C; BASKET-LATE Investigators: Late clinical events after clopidogrel discontinuation may limit the benefit of drug-eluting stents: An observational study of drug-eluting versus bare-metal stents. J Am Coll Cardiol 48: 2584-2591, 2006.

19. Nebeker JR, Virmani R, Bennett CL, Hoffman JM, Samore MH, Alvarez J, Davidson CJ, McKoy JM, Raisch DW, Whisenant BK, et al: Hypersensitivity cases associated with drug-eluting coronary stents: A review of available cases from the Research on Adverse Drug Events and Reports (RADAR) project. J Am Coll Cardiol 47: 175-181, 2006.

20. Finn AV, Nakazawa G, Joner M, Kolodgie FD, Mont EK, Gold HK and Virmani R: Vascular responses to drug eluting stents: Importance of delayed healing. Arterioscler Thromb Vasc Biol 27: 1500-1510, 2007.

21. Shiratori Y, Cola C, Brugaletta S, Alvarez-Contreras L, Martín-Yuste V, del Blanco BG, Ruiz-Salmeron R, Díaz J, Pinar E, Martí V, García-Picart J and Sabaté M. Randomized comparison between polymer-free versus polymer-based paclitaxel-eluting stent: Two-year final clinical results. Circ Cardiovasc Interv 7: 312-321, 2014.

22. Zhang Y, Chen F, Muramatsu T, Xu B, Li Z, Ge J, He Q, Yang Z, Li S, Wang L, et al: Nine-month angiographic and two-year clinical follow-up of polymer-free sirolimus-eluting stent versus durable-polymer sirolimus-eluting stent for coronary artery disease: The Nano randomized trial. Chin Med J (Engl) 127: 2153-2158, 2014 
23. John MC, Wessely R, Kastrati A, Schömig A, Joner M Uchihashi M, Crimins J, Lajoie S, Kolodgie FD, Gold HK, et al: Differential healing responses in polymer- and nonpolymer-based sirolimus-eluting stents. JACC Cardiovasc Interv 1: 535-544, 2008.

24. Chen BX, Ma FY, Luo W, Ruan JH, Xie WL, Zhao XZ, Sun SH, Guo XM, Wang F, Tian T and Chu XW: Neointimal coverage of bare-metal and sirolimus-eluting stents evaluated with optical coherence tomography. Heart 94: 566-570, 2008

25. Mandelias K, Tsantis S, Spiliopoulos S, Katsakiori PF, Karnabatidis D, Nikiforidis GC and Kagadis GC: Automatic quantitative analysis of in-stent restenosis using FD-OCT in vivo intra-arterial imaging. Med Phys 40: 063101, 2013.
26. Bezerra HG, Costa MA, Guagliumi G, Rollins AM and Simon DI: Intracoronary optical coherence tomography: A comprehensive review clinical and research applications. JACC Cardiovase Interv 2: 1035-1046, 2009.

27. Jia H, Liu H, Kong J, Hou J, Wu J, Zhang M, Tian J, Liu H, Ma L, $\mathrm{Hu} \mathrm{S}$, et al: A novel polymer-free paclitaxel-eluting stent with a nanoporous surface for rapid endothelialization and inhibition of intimal hyperplasia: Comparison with a polymer-based sirolimus-eluting stent and bare metal stent in a porcine model. J Biomed Mater Res A 98: 629-637, 2011. 